\title{
Los anglicismos en la prensa deportiva de los 50
}

\author{
Anglicisms in the 50's sport press \\ María Vásquez Amador, Carmen Lario y Paloma López \\ Universidad de Cádiz, Facultad de Ciencias Económicas y Empresariales, \\ Facultad de Ciencias Sociales y de la Comunicación, Jerez de la Frontera, España. \\ Correos electrónicos: maria.vazquez@uca.es,carmen.lario@uca.es y paloma.lopez@uca.es
}

\begin{abstract}
El deporte, uno de los fenómenos sociales de mayor relevancia hoy en día, tiene un origen angloamericano, consecuentemente, los primeros términos deportivos llegaron al resto de las lenguas directamente en inglés, es decir, como anglicismos. El objetivo de este trabajo es identificar estas voces y observar la evolución que han tenido en el español hablado a ambos lados del Atlántico. Mediante la lectura de tres periódicos deportivos publicados en México, Argentina y España a mitad del siglo XX se analizarán a nivel formal los anglicismos encontrados, y se determinará el grado de aceptación e incorporación de éstos tanto en el Diccionario de Americanismos publicado en 2010, como en la edición actual del Diccionario de la Lengua Española.
\end{abstract}

Palabras clave: anglicismos, español peninsular, español de América, lenguaje deportivo, diccionarios

Sports, one of the most relevant phenomena nowadays, has an Anglo-American origin, thus, the first sports terms reached the rest of the languages in English, that is, as Anglicisms. This paper aims to identify those words and observe the development they have suffered in the Spanish language spoken on both sides of the Atlantic. Through the analysis of three newspapers edited in Mexico, Argentina and Spain in the mid-20th century, the Anglicisms found will be formally analyzed and the degree of acceptance and admission in two dictionaries The Dictionary of Americanisms, published in 2010 and the Dictionary of the Spanish Royal Academy, published in 2001 will be determined.

Key words: Anglicisms, European Spanish, American Spanish, sports language, dictionaries

\section{INTRODUCCIÓN}

El deporte es uno de los fenómenos de masas más influyentes en nuestra sociedad hoy en día. Una de sus principales características es la presencia de voces procedentes de la lengua inglesa, debido al origen angloamericano de éste. 
El protagonismo del anglicismo en el deporte no viene sólo por la influencia de los países de habla inglesa en nuestra vida política y cultural, sino y sobre todo porque buena parte de los deportes que se practican hoy, y de manera especial los que cuentan con más seguidores y más impacto mediático, son de origen anglo-norteamericano. Aparte del fútbol, y su pariente el rugby, cabe pensar en el baloncesto, el balonvolea o voleibol, el tenis, el golf, entre otros (Rodríguez González 2012: 286).

El deporte de equipos tiene su origen en la Inglaterra de finales del siglo XVIII, y se expande en el siglo XIX, fundamentalmente, a través de los jóvenes estudiantes de la burguesía.

Ya en el siglo XIX comenzó a valorarse como un complemento imprescindible para la forja del carácter de los jóvenes de los colleges que posteriormente debían nutrir las elites gobernantes, la práctica de nuevas actividades deportivas, que inculcaran valores como la disciplina, el afán de superación, el sacrificio, la camaradería, el espíritu de equipo, fomentando la rivalidad entre los alumnos y entre los colleges (Otero Carvajal 2003: 173).

En poco tiempo se extendió a todas las esferas y capas de la sociedad británica, tal como indica Olivera Beltrán: "La clase popular, en el último tercio del siglo XIX, se adhirió con pasión al movimiento deportivo, creando nuevos equipos y clubes en las ciudades industriales, sobre todo de fútbol, que pronto se impusieron a los equipos de los gentlemen" (1993: 21). Asimismo, entre finales del siglo XIX y principios del siglo XX, el fenómeno del deporte se expandió por el resto de Europa, llegando a España a través de las clases altas que, admiradoras de la sociedad británica, aspiraban a imitar sus costumbres.

\begin{abstract}
A finales del siglo XIX, miembros de la aristocracia y de la burguesía de Madrid y Barcelona comenzaron a practicar el sport inglés como una actividad distinguida y de signo social diferenciador. (...) Posteriormente, la pequeña burguesía y la clase media, profesionales liberales, funcionarios, comerciantes, administrativos, empleados de la banca, etc., de los núcleos urbanos antes citados (y de otros), comenzaron a ejercitarse en las prácticas físicas y deportivas. (...) Era una forma de emular a las clases altas y de acercarse a los hábitos de vida modernos y distinguidos que la sociedad anglosajona, tan admirada entonces en España, exportaba al resto del mundo: un fin higiénico y cierto prestigio social marcaban el sentido de las prácticas deportivas (Rivero Herraiz 2004: 29).
\end{abstract}

Como ya ocurrió en Inglaterra, poco después las clases populares comenzaron también a practicar principalmente deportes de competición como el atletismo, la natación y el ciclismo. Los deportes-espectáculo como el fútbol y el boxeo lograron multitud de aficionados, mayoritariamente entre las clases más populares (Olivera Beltrán 1993).

Pronto el imperio británico extendió la práctica deportiva por otros continentes. Los deportes llegaron a México de la mano de los extranjeros a finales del siglo XIX. Estas nuevas costumbres fueron pronto adoptadas por las clases altas mexicanas, que comenzaron a practicar los deportes traídos de Europa y Estados Unidos.

La élite local y las comunidades extranjeras se entretenían en clubes y casinos privados, donde practicaban una miríada de actividades físicas que habían sido importadas de Europa o de los Estados Unidos: golf, tenis, fútbol, gimnasia, esgrima, patinaje, polo, equitación, regatas, etcétera (Pasteur 2011: 9). 
La difusión masiva del deporte llegó a Argentina un poco más tarde, a principios del siglo XX, a través de la comunidad británica que difundió la práctica del polo, el fútbol, el rugby y el hockey sobre césped. Asimismo, se empezaron a practicar otras disciplinas deportivas como el boxeo, el ciclismo, la gimnasia artística, el automovilismo y la aviación. Los británicos se enorgullecían de haber llevado al país no sólo capitales, industria, nueva tecnología, nuevas razas, vacunas y lanares, sino también el gusto y la pasión por los deportes que permitieron el desarrollo moral de la juventud (The Standard 1/1/1913: 22 Cit. en Archetti 2005: 1-2).

Con la llegada del deporte a cada uno de estos países, se adoptaron sus reglas y, con ellas, toda la terminología en inglés referente a cada una de las disciplinas: "Debido al hecho de que el idioma oficial en el deporte es el Inglés, es muy probable que se incluya un número considerable de préstamos léxicos del Inglés en la terminología de los deportes no ingleses" (Milic 2013: 66) ${ }^{1}$.

La edición actual del diccionario de la Real Academia (2001) define los anglicismos como:

- 1. m. Giro o modo de hablar propio de la lengua inglesa.

- 2. m. Vocablo o giro de esta lengua empleado en otra.

- 3. m. Empleo de vocablos o giros ingleses en distintos idiomas.

Por anglicismo entendemos las voces de procedencia inglesa que otras lenguas adoptan, normalmente para nombrar un concepto desconocido, o por otra serie de causas lingüísticas como el uso de sinónimos y efectos estilísticos. En el momento en que los anglicismos se incorporan a la lengua, su futuro es incierto, siendo un factor de suma importancia su frecuencia de uso. Cuanto mayor sea su grado de frecuencia, mayor será la probabilidad de instalarse en la lengua. Cuando estas voces permanecen en la lengua receptora pueden transformarse para asimilarse a las reglas ortográficas de ésta o mantener la grafía inglesa, e igualmente pueden conservar el significado original con el que llegaron a la lengua española o pueden modificarlo. Por el contrario, en otras ocasiones, la vida de estos anglicismos es efímera y desaparecen al caer en desuso o al ser sustituidos por vocablos autóctonos.

Son muchos los autores que han estudiado la presencia de los anglicismos en el mundo deportivo en España (Alzugaray 1982; García Yebra 1992; Lázaro Carreter 1994; Alonso Pascual 1996; Alvar Esquerra 2009; Lario de Oñate y Vázquez Amador 2010), y en distintos países hispanoamericanos (Contreras 1953; Luna Traill 1998; González Gómez 2000; Archetti 2005; Pasteur 2011; Rodríguez González 2012). Algunos de ellos los han estudiado en el deporte en general, a ambos lados del Atlántico, tal como Luna Traill (1998), quien hace un estudio sobre los anglicismos deportivos encontrados en doce ciudades hispanohablantes; Nomdedeu-Rull (2001, 2002, 2003; Torrebadella-Flix y Nomdedeu-Rull 2013) tiene diversas publicaciones, tanto del deporte en general como del fútbol en particular, en las que analiza la terminología deportiva y observa cómo se representa en diccionarios de lengua española, y; Castañón Rodríguez $(1987,1992,1998,2000,2011)$ lleva a cabo numerosos estudios sobre los anglicismos, tanto en el mundo deportivo como en el mundo del fútbol, y ha realizado diferentes glosarios sobre diversas disciplinas deportivas.

"Due to the fact that the official language of sport is English it is quite likely that non-English Sports terminologies include a considerable number of lexical borrowings from English". 
En este estudio se investigaron los anglicismos localizados en tres periódicos deportivos publicados respectivamente en España, México y Argentina a mediados del siglo pasado, con el objetivo de comparar si hay variaciones en cuanto al número, la tipología, la disciplina deportiva y la admisión de estas voces en los diccionarios.

La mayoría de las clasificaciones publicadas sobre anglicismos son formales, y los autores se basan en las características ortográficas y sus diferencias con las reglas de la lengua receptora para describirlos. La metodología al respecto no es uniforme y no hay una terminología unánime. Gómez Capuz (1997) se refiere, entre otras razones, a la variedad de criterios para diseñar las clasificaciones, y enfatiza la importancia de tener en cuenta la dimensión sociolingüística del fenómeno de los préstamos.

La Lingüística General aún se encuentra en búsqueda de una clasificación general válida de los préstamos lingüísticos o interferencias, esto es, el intercambio de material lingüístico entre dos variedades de discurso, principalmente dos lenguas (...) Primero, se pueden proponer muchas maneras de clasificar los tipos de contacto lingüístico (...) Es más, estas clasificaciones han sido concebidas como artificiales y carentes de completa validez, ya que nosotros los lingüistas proponemos categorías discretas que no pueden englobar todos los factores envueltos en una situación sociolingüística determinada (Gómez Capuz 1997: 81-82)².

Dadas las características del corpus analizado hemos decidido mantener nuestra clasificación en el nivel formal, basándonos principalmente en las tipologías de Lorenzo (1987) y de Pratt (1980). Lorenzo divide los anglicismos según el modo de penetración en la lengua española y su grado de adaptación a ésta. Los anglicismos crudos "son aquellas palabras o expresiones que mantienen en español la grafía inglesa y un reflejo de pronunciación más o menos inglesa" (1987: 74). Los anglicismos en período de aclimatación son vocablos cuya grafía o pronunciación está en proceso de adaptación a las normas españolas. Se consideran anglicismos totalmente asimilados las voces que en el pasado penetraron en el español directamente del inglés o mediante el francés y que hoy en día ya están completamente integradas en el léxico español. Los calcos son palabras que expresan conceptos desconocidos en el idioma receptor en el momento de la penetración. Y los calcos semánticos son, en este caso, las expresiones españolas que adquieren un nuevo significado que antes no tenían.

Pratt (1980), por su parte, divide los anglicismos según el número de elementos que conformen el término: univerbales y multiverbales. Los univerbales, a su vez, los subdivide en anglicismos patentes, formas identificables como inglesas que pueden tener grafías aceptables o no aceptables para la lengua española, y anglicismos no patentes, los cuales se reconocen como voces españolas que adquieren un nuevo matiz, o neologismos procedentes de voces grecolatinas que no tienen, por tanto, apariencia inglesa. Los anglicismos multiverbales consisten en la traducción al español de voces bimembres inglesas (Pratt 1980: 185).

Los anglicismos que se encontraron en el estudio se registraron teniendo en cuenta el grado de asimilación de éstos con respecto a la lengua española. Aunque existe

\footnotetext{
"General Linguistics is still in search of a valid general classification of linguistic borrowing or interference, that is, the exchange of linguistic material between two varieties of speech, mainly two languages (...) Firstly, several ways of classifying linguistic contacts can be devised, and these ways (...) Moreover, these classifications are felt to be artificial and lacking full validity, as we linguists propose discrete categories that cannot embrace all the factors involved in a given socio-linguistic situation".
} 
mayor diversidad dentro de la tipología de anglicismos, a continuación se nombran exclusivamente los que aparecieron en el corpus objeto de estudio.

- Los anglicismos crudos son gráficamente iguales a la voz de procedencia (e.g. cross, singles y crack).

- Los falsos anglicismos son palabras que no existen en inglés a pesar de estar formadas por lexías inglesas (e.g. basketballer).

- Los anglicismos hipercaracterizados son aquellas voces que parecen más inglesas que la grafía original (e.g. flay, procedente de la voz inglesa $f y$ ).

- Los anglicismos parcialmente asimilados al español son vocablos cuya grafía aún mantiene elementos extranjeros, normalmente porque se han adaptado a la pronunciación inglesa (e.g. tim procedente de la voz inglesa team).

- Los anglicismos híbridos están formados por dos lexías, una española y una inglesa (e.g. centro-forward).

- Los anglicismos derivados son aquellas voces formadas por derivación de un anglicismo, y que mantienen elementos extranjeros (e.g. waterpolista).

- Los anglicismos asimilados ya están totalmente adaptados a la ortografía española (e.g. réferi procedente de referee y oper procedente de upper).

- Los calcos léxicos son vocablos bimembres traducidos del inglés (e.g. guardavalla y sobretodo).

En este trabajo se pretende analizar la aparición de estos anglicismos a través de tres periódicos publicados en España, México y Argentina, medio siglo después del comienzo de la difusión del deporte a nivel internacional. Nos planteamos si el número de anglicismos será similar en cada uno de los periódicos y en cada una de las disciplinas deportivas estudiadas. Asimismo, nos cuestionamos si los anglicismos se habrán adaptado a la lengua española, o habrán sido sustituidos por voces autóctonas, pues como indica Rodríguez González: "La historia nos enseña que los nombres de los deportes, una vez puestos en circulación, resultan difíciles de erradicar pues los hablantes, sobre todo los que los practican, se aferran a la denominación inglesa como si se tratara de una marca registrada" (2012: 286). Nos preguntamos si estas variaciones son similares en los tres ejemplares, o si, a pesar de tener como lengua común el español, se han adoptado mecanismos distintos en cada una de las comunidades lingüísticas.

Los anglicismos, por su naturaleza, dan lugar a variaciones lingüísticas en muy diferentes niveles (léxico, morfológico, fonológico, etc.) (...) en el nivel léxico, las variaciones que resultan de adoptar el término propiamente anglicista, o bien su correspondiente calco o traducción (...) Otro nivel de variación aún más visible tiene lugar en la morfología y la ortografía de algunos términos (...) Las fluctuaciones son de esperar especialmente cuando se trata de adaptar la grafía de un anglicismo que no está totalmente integrado en nuestra lengua (...) (Rodríguez González 2007: 12).

\section{Metodología}

Para llevar a cabo este estudio se procedió al análisis de tres periódicos publicados a mitad del siglo XX en tres países hispanohablantes. Estos periódicos tenían una extensión de aproximadamente veinte páginas e incluían artículos sobre diversos deportes y también anuncios publicitarios. Los periódicos fueron: el Gráfico de 1945, 
publicación fundada en 1919 y considerada la más influyente en el ámbito deportivo en el siglo XX en Argentina (Bergel y Palomino 2000); el periódico deportivo La Afición de 1950, publicado por primera vez en 1930 y considerado como una verdadera escuela de periodismo deportivo en México (Caloca Carrasco 2003); y el Mundo Deportivo de 1955, decano de la prensa deportiva en España, publicado por primera vez en 1906 y vigente en la actualidad (Sainz de Baranda 2013).

La metodología seguida consistió en la lectura de los textos, la anotación de los anglicismos encontrados y la clasificación de éstos según los criterios que a continuación se mencionan.

- Anglicismos encontrados en cada periódico: con el fin de determinar si se observaron diferencias geográficas en cuanto a las disciplinas deportivas, la tipología y la admisión en el Diccionario de la Lengua Española (DRAE) de los anglicismos.

- Disciplina a la que pertenecen los anglicismos: deportes (baloncesto, béisbol, boxeo, deportes acuáticos, fútbol, hípica y rugby); otros deportes; voz deportiva y voz no deportiva.

Como se explicó en el apartado anterior, los anglicismos se clasificaron formalmente en: anglicismos crudos, asimilados, parcialmente asimilados, derivados, calcos léxicos, falsos anglicismos, híbridos e hipercaracterizados.

- Admisión en el diccionario: todos los anglicismos se buscaron en la edición actual del DRAE, la obra de referencia de la Real Academia de la Lengua Española en su versión online. Asimismo, se buscaron en el Diccionario de Americanismos (DA), un diccionario descriptivo diseñado por la Asociación de Academias de la Lengua Española que pretende recoger todas las palabras propias del español de América.

\section{ANÁLISIS y RESULTADOS}

En toda la muestra se localizaron un total de 133 anglicismos, de los cuales 28 se encontraban en, al menos, dos de los periódicos. Por ejemplo, los anglicismos boxeo, gol, corner y handicap se localizaron en los tres periódicos estudiados, y los anglicismos single y team en el periódico argentino y en el mexicano. La diferencia entre el número de anglicismos hallados en cada uno de los periódicos es bastante significativa, pues se encontraron un total de 83 anglicismos en el periódico mexicano, 57 anglicismos en el argentino, y tan sólo 33 voces en el español. Como se muestra en la Tabla 1, más del $62 \%$ del total de anglicismos encontrados estaba en la prensa mexicana, algo más del $42 \%$ de esas 133 voces se localizó en la argentina, y tan sólo el 21,8\% en la española.

Tabla 1: Anglicismos localizados

\begin{tabular}{|l|c|c|}
\hline Periódico & $\mathbf{N}^{\mathbf{0}}$ anglicismos & Porcentaje \\
\hline La Afición (México) & 83 & $62 \%$ \\
\hline Gráfico (Argentina) & 57 & $42 \%$ \\
\hline Mundo Deportivo (España) & 33 & $21,8 \%$ \\
\hline
\end{tabular}




\section{1. Áreas temáticas}

Estos anglicismos pertenecían a distintas disciplinas deportivas que se observan en la Tabla 2, siendo los más numerosos los relacionados con el fútbol, el boxeo, el béisbol y el rugby.

Tabla 2: Anglicismos clasificados por deporte según número de apariciones

\begin{tabular}{|l|c|c|c|}
\hline Deporte & $\begin{array}{c}\text { La Afición } \\
\text { (México) }\end{array}$ & $\begin{array}{c}\text { Gráfico } \\
\text { (Argentina) }\end{array}$ & $\begin{array}{c}\text { Mundo Deportivo } \\
\text { (España) }\end{array}$ \\
\hline Fútbol & 6 & 14 & 8 \\
\hline Voz no deportiva & 8 & 6 & 7 \\
\hline Boxeo & 10 & 8 & 5 \\
\hline Béisbol & 22 & 2 & 0 \\
\hline Rugby & 13 & 9 & 0 \\
\hline Voz deportiva & 11 & 7 & 2 \\
\hline Otros deportes & 4 & 2 & 9 \\
\hline Baloncesto & 4 & 3 & 1 \\
\hline Deportes acuáticos & 0 & 5 & 0 \\
\hline Hípica & 4 & 1 & 1 \\
\hline
\end{tabular}

Fue en la disciplina del fútbol en la que se encontró un número más alto de anglicismos, localizándose varios en cada uno de los periódicos, y siendo el argentino el que más voces registró. Los anglicismos que se repiten en los tres periódicos son futbol, corner y gol; en el periódico mexicano y español se encuentra el anglicismo penalty; en Argentina y en España las voces crack y futbolístico, y el anglicismo parcialmente asimilado chut, encontrado como anglicismo crudo, shot, en Argentina. En el periódico mexicano también se encontraron los anglicismos referi y soccer; en Argentina casi todas las posiciones de los futbolistas (back, centroforward, half, insider, goalkeeper y guardavallas), y las voces ball y goleador. En el periódico español se localizó el anglicismo creado por derivación, antifútbol. A continuación se muestra un fragmento del Gráfico en el que aparecen diversos anglicismos relacionados con el fútbol.

En una defensa segura y compacta los halves fueron lo mejor, al punto que allí se elaboró la victoria. Además los forwards se mostraron codiciosos, penetrantes y remataron de diferentes ángulos hasta convertir en el primer tiempo al goalkeeper Musimesi en el mejor hombre del team rosarino. (...) Un centro de Camer es muy bien cabeceado por Barreiro y Musimesi con un shot después de haber hecho picar la pelota... y la ball le pega en la espalda a Barreiro que se dirigía al centro del field (Gráfico 1945: s/p) ${ }^{3}$.

\footnotetext{
Este periódico no está paginado.
} 
El grupo de anglicismos no deportivos es bastante significativo en los tres periódicos, fundamentalmente en el mexicano. Algunos de éstos eran voces utilizadas en el contexto del deporte, mientras que otros eran voces generales encontradas en su mayoría en anuncios publicitarios. En los tres periódicos aparece la voz $c l u b$, y en los de España y México se repiten líder y yarda. En el periódico mexicano también se encontraron fan, ponche, clown, rol y elevadorista. En el argentino se registraron performance, standard, sobretodo, lunch y cocktail. Los anglicismos no deportivos de la prensa española eran comité, interviú, jersey y film. En el ejemplo que sigue se observa el uso del anglicismo yarda acompañado de otros anglicismos deportivos.

Quien jugó como tailback en una formación nada familiar para él, la doble ala del coach Matty Bell. A pesar de la desventaja, Lebaron fue virtualmente la única amenaza sólida del Oeste. El formidable enano del fútbol, avanzó 35 yardas en 11 intentos por línea para un promedio de 7.7 ; completó siete de los 12 pases y personalmente dirigió a su tim en la consumación de su único touchdown (La Afición 1950: 6).

Aunque el número de anglicismos vinculados al béisbol era muy alto, la mayoría se localizó en la prensa mexicana, con un total de 23 voces: average, bateo, béisbol, fildeador, fildeo, flay, foul, hit, home run, innings, jonrón, leftfield, out, outfield, pasbol, pitcheo, pitcher, short, softbol, standing, swing y wild; y tan sólo dos en la prensa argentina, foul y el crudo softball, que coincide con el anglicismo parcialmente adaptado softbol encontrado en el periódico mexicano. En el Mundo Deportivo no se detectó ningún anglicismo ni referencia alguna a este deporte. "Camacho y Kiko dieron hits en la octava entrada, siendo impulsados al pentágono por hit del pitcher Cochihuila. Tijuana se había hecho una en el segundo inning al llegar Hughes hasta la tercera base por error anotando en pasbol" (La Afición 1950: 12).

Con respecto al boxeo, fueron varios los anglicismos encontrados en los tres periódicos. Coinciden en los tres corpus los anglicismos boxeador, boxeo y ring. Los anglicismos box y round se repiten en el periódico mexicano y argentino, al igual que el anglicismo asimilado noquear en México, que aparece como anglicismo crudo, knockout, en Argentina. Otros anglicismos relacionados con el boxeo fueron oper (procedente de upper), nelson, welter y boxer en México; punch y boxístico en Argentina; y gongo y catcher en España, los que se muestran en el ejemplo que se presenta a continuación.

Tenemos garantizado un combate de gran emoción desde el primer tañido del gongo, fácil de pronosticar dadas las características de uno y otro luchador. Y es precisamente por esa similitud de estilos, por esa semejanza de comportarse sobre el ring entre Jim Oliver y Echevarría, la razón y el motivo de esperar una gran batalla entre ambos catchers (Mundo Deportivo 1955: 1).

Algo similar ocurre con los anglicismos relacionados con el rugby, que sólo se localizaron en el periódico mexicano y en el argentino con tan sólo dos coincidencias, fullback y rugby; en la prensa mexicana también se encontraron los anglicismos back, backfield, coach, down, halfback, quarterback, singlewing, tackle, tailback, touch y touchdown; y en la argentina: forward, handling, scrum, scrumhalf, touch, try y winger. 
Una de las muchas y excelentes aperturas realizadas por Ezequiel Holmberg, scrumhalf de C.U.B.A., al taconear sus forwards en un scrum fijo (...) Cendoya consigue patear al touch en un momento de apremio para su equipo. Gamalero se ha zambullido para tratar de interceptar la pelota pero no consigue hacerlo. Más atrás aparece el fullback de C.U.B.A. (...) (Gráfico 1945: s/p).

Asimismo, aparecieron una serie de voces deportivas generales utilizadas en distintos deportes, las que fueron más numerosas en el periódico mexicano. Tan sólo se repite en los tres periódicos el anglicismo handicap. Cinco anglicismos coinciden en los periódicos mexicano y argentino: field, manager, match, single y team. Los otros anglicismos que se encontraron son bowl, manager, player, record y score en el periódico mexicano, shot en el argentino, y recordman en el español.

Los anglicismos relacionados con el baloncesto que aparecieron en los tres periódicos eran distintas variaciones léxicas procedentes de la voz inglesa basketball. Coincidieron en el periódico mexicano y argentino los anglicismos basket y basketball, y en el periódico mexicano y en el español baloncesto. También se encontraron las voces basquetbol en el mexicano y basketballer en el argentino.

En cuanto a los anglicismos relacionados con la hípica, se encontraron un total de cinco, cuatro de ellos en el periódico mexicano: tiemop, entry, handicapper y furlong, y uno, turf, en el periódico argentino.

Con respecto a los deportes acuáticos, se localizaron cinco en el periódico argentino, dos relacionados con el remo, pack y rowing, y tres de ellos con la navegación, yachting, yachtsman y yacht, que coinciden con yate, encontrado en el periódico español. "Aparte del remo, cuenta el club con una sección de yachting, que dispone de barcos propios de la Clase Argentina, siendo muchos los socios que han intervenido con suertes diversas en casi todas las regatas que para barcos de esta clase se han efectuado" (Gráfico 1945: s/p).

Asimismo, se hallaron anglicismos relacionados con otros deportes. El anglicismo hockey se encontró en el periódico mexicano y en el español. Vinculados al tenis, se registró el anglicismo tenis en el periódico mexicano, tenis y court en el argentino, y tenis mesa en el español. En la prensa española se localizaron dos anglicismos del mundo del motociclismo, ciclocross, ciclocrossman; dos relacionados con el atletismo, cross, que coincide en el mismo texto con el calco léxico campo a través, ambos procedentes de la voz inglesa cross-country; uno relacionado con el ciclismo, sprinter; y uno con el waterpolo, waterpolista. El periódico mexicano registró dos anglicismos relacionados con el voleibol, volibol y volibolera, y el español uno, balon bolea, curiosamente escrito con b.

En resumen, podemos decir que el número de anglicismos que coincide en cada uno de los tres corpus no es demasiado elevado, siendo estas coincidencias algo más frecuentes en las disciplinas de fútbol, boxeo y las voces deportivas generales. En cuanto a la coincidencia de anglicismos por países, aunque hay varios que se repiten en los periódico de México y España, y Argentina y España, es principalmente en los ejemplares de Argentina y México donde se encuentran más anglicismos comunes.

\subsection{Tipología}

Con respecto a la tipología de los anglicismos estudiados en este trabajo, se encontraron anglicismos crudos, parcialmente adaptados, asimilados, calcos 
léxicos, voces derivadas de anglicismos, falsos anglicismos, híbridos y anglicismos hipercaracterizados. En líneas generales, los anglicismos localizados en el estudio son en su mayoría crudos, con un total de 86 voces que representan el $64,7 \%$ del total. También apareció un número bastante representativo de anglicismos asimilados (15\%), y voces derivadas de anglicismos (6,8\%). El resto de los anglicismos pertenecientes a otras tipologías no eran demasiado numerosos, como se muestra en el Gráfico 1.

Gráfico 1: Tipología de los anglicismos

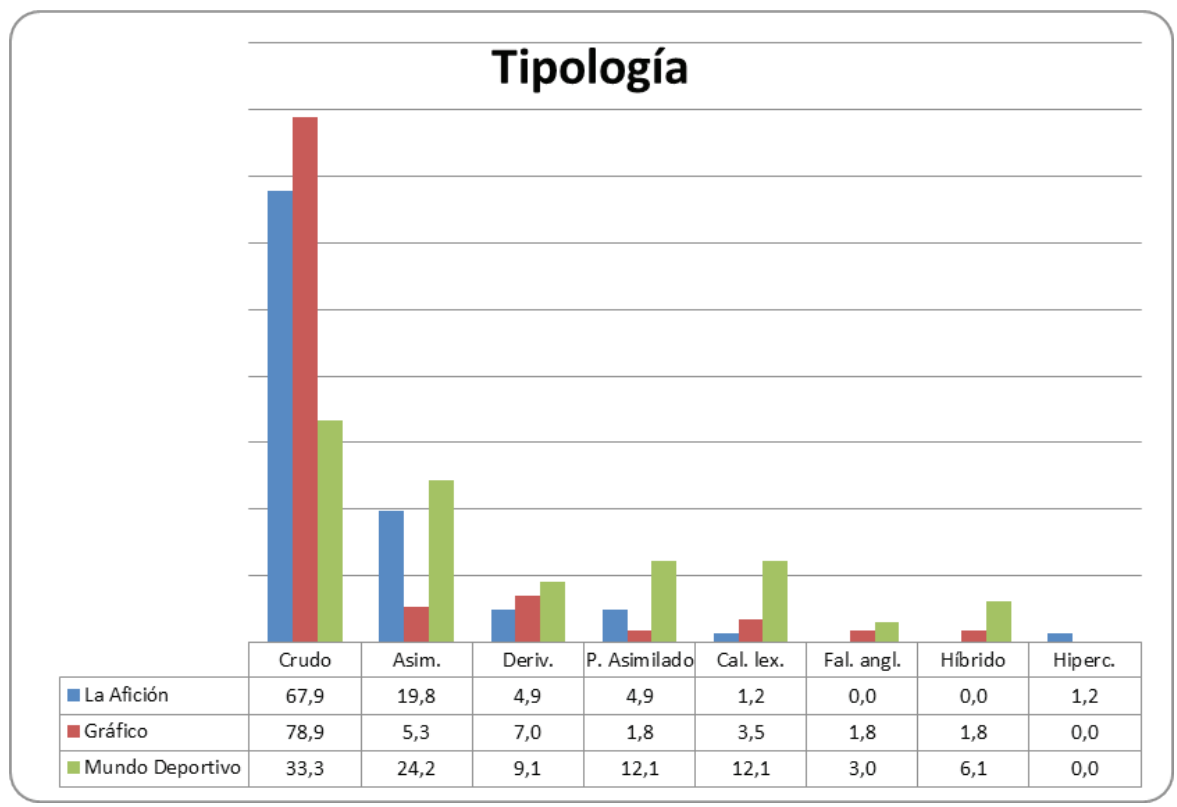

Aunque la mayor parte de éstos son crudos, gráficamente exactos a la voz inglesa de procedencia, se hallaron diferencias muy representativas en cada uno de los corpora. Mientras en el argentino los anglicismos crudos representaban el 78,9\% de las voces encontradas como goalkeeper, knockout, turf, handling y winger, y en el mexicano un $67,9 \%$ con anglicismos como average, pitcher, nelson, backfield y tailback, en el periódico español tan sólo se registraron un 33,3\% de anglicismos crudos como catcher, crack y ring. Rodríguez González (2007) justifica este fenómeno por causas políticas debidas a la dictadura franquista en la que hubo un intento de nacionalizar la terminología foránea, incluida la deportiva.

Con respecto a los anglicismos asimilados, el porcentaje de éstos era bastante alto en el periódico español, con voces como boxeo, gongo y yarda; y en el periódico mexicano, con anglicismos como jonrón, noquear y oper, dato que contrasta con el corpus argentino, que tan sólo registra un 5,3\% con los anglicismos boxeo, gol y tenis. En cuanto a las voces formadas por derivación de anglicismos, éstas eran más prominentes en la prensa española, con ejemplos como antifútbol y waterpolista; un $7 \%$ se registró en la prensa argentina con ejemplos como boxeador y goleador; y tan 
sólo se detectó un 4,9\% de estos anglicismos en la prensa mexicana, entre otros, con ejemplos como fildeador y elevadorista. Fue también en la prensa española donde se encontró un porcentaje más alto de anglicismos parcialmente adaptados como chut, futbol e interviú; un 4,9\% se halló en la prensa mexicana, con ejemplos, entre otros, como pitcheo y softbol; y un 1,8\% en la prensa argentina, representado en la voz futbol. En el periódico español aparecieron cuatro calcos léxicos, balon bolea, baloncesto, campo a través y tenis mesa; dos en el periódico argentino, guardavallas y sobretodo; y baloncesto en el mexicano. Un falso anglicismo se observó en el periódico argentino, basketballer; y uno en el español, recordman. Se identificaron tres anglicismos híbridos, ciclo-cross y ciclo-crossman en la prensa española; y centroforward en el medio argentino. Y se encontró un anglicismo hipercaracterizado, flay, en el periódico mexicano.

En este último, la mayoría de los anglicismos eran crudos, el 67,9\%, aunque el porcentaje de anglicismos ya asimilados es bastante alto, casi el $20 \%$, siendo muchos de éstos muy populares a nivel internacional (béisbol, boxeo, bateo, gol, líder, tenis, volibol, rol y yarda), y otros menos conocidos, que en varios casos coinciden con el anglicismo crudo procedente de la misma voz inglesa, como fildeo y field, jonrón y homerun, noquear y knockout. Las demás tipologías de anglicismos no son demasiado representativas. Tan sólo cuatro son anglicismos parcialmente adaptados, dos de ellos muy internacionales, basquetbol y futbol, y otros dos que coincidían con los anglicismos crudos de la misma voz de procedencia, softbol y softball, y tim y team; cuatro voces derivadas de un anglicismo, boxeador, que coincide con box, elevadorista, procedente de elevator, fildeador, que se corresponde con field y volibolera, y con el anglicismo asimilado volibol.

Estos datos demuestran el dinamismo de la lengua española que hace suyos los anglicismos y los utiliza para la formación de derivados. Tan sólo se encontró un calco léxico, baloncesto, que coincide en las mismas páginas del periódico con el anglicismo crudo y con el anglicismo en periodo de aclimatación procedentes de la misma voz de origen; y un anglicismo hipercaracterizado, flay.

Aunque el corpus mexicano está formado principalmente por anglicismos que aún no han sido adaptados a la lengua española, también se encuentra un grupo de anglicismos que ya están asimilados o en proceso de aclimatarse a nuestro idioma, y que aún coinciden con los anglicismos crudos, demostrando la versatilidad de nuestro idioma y las distintas "versiones". Si se compara la tipología de los anglicismos con la disciplina a la que pertenecen, es llamativo cómo todos los anglicismos relacionados con el rugby son crudos, quizá por la influencia directa de los Estados Unidos, y por el hecho de no ser un deporte popular en España (recuérdese que no se encontró ninguna voz relacionada con este deporte en los ejemplares revisados de Mundo Deportivo).

En el periódico argentino analizado se localizaron en total 57 anglicismos, de los cuales la inmensa mayoría estaba en estado crudo, casi un $80 \%$. Se encontraron cuatro voces derivadas de un anglicismo, dos de las cuales, boxístico y boxeador, coincidían con el crudo box, futbolístico, con el anglicismo en periodo de aclimatación futbol, y goleador con gol. Tan sólo se hallaron tres anglicismos asimilados, nuevamente voces muy populares a nivel internacional, boxeo, gol y tenis; dos calcos léxicos, sobretodo y guardavalla, que coincide en el periódico con el crudo goalkeeper; un anglicismo en periodo de aclimatación, futbol; un falso anglicismo, basketballer; y 
un híbrido, centro-forward. Como ya ocurrió en el corpus mexicano, en todos los anglicismos relacionados con el rugby las voces deportivas son crudas.

En el periódico español tan sólo se encontraron 33 anglicismos, el 33,3\% de ellos eran crudos, como hockey o handicap, un porcentaje mucho más bajo que en los periódicos americanos. En cambio, el número de anglicismos asimilados es bastante elevado, un $27,6 \%$, con ejemplos como yate, esprinter y yarda. Se encontraron varias voces derivadas de anglicismos como boxeador y futbolístico, cuatro calcos léxicos, baloncesto, balonbolea, campo a través y tenis mesa, y dos anglicismos parcialmente adaptados como interviú y chut. Asimismo, se localizaron en el periódico dos anglicismos híbridos, ambos formados por la lexía española "ciclo" y las lexías inglesas cross y crossman, y el falso anglicismo recordman. En general, no se encontraron coincidencias entre anglicismos crudos y otros más asimilados en este periódico.

\subsection{Admisión en los diccionarios}

En cuanto a la admisión de los anglicismos en el diccionario, éstos se buscaron en las versiones en línea del Diccionario de Americanismos (DA) y del Diccionario de la Lengua Española (DRAE), ambos editados por la Real Academia de la Lengua Española. Del total de anglicismos encontrados, 65 se encuentran registrados en el DA como "procedentes del inglés" (10), voz autóctona (18), voz inglesa (34), y 3 de ellos después de una adaptación en la grafía. Casi el 50\% de estos anglicismos (30) se localizó exclusivamente en el periódico mexicano, 14 de ellos en el periódico argentino, 3 en el español, y los 18 restantes en al menos dos de estos periódicos. De estos 63 anglicismos, 33 también están admitidos en el DRAE, y se caracterizan por ser mayoritariamente anglicismos gráficamente adaptados al español (asimilados, calcos léxicos y derivados), aunque también se admite un número representativo de anglicismos crudos muy internacionales (basket, club, record y standard) que pertenecen a distintas áreas, pese a que destacan las voces generales.

Varios de estos anglicismos tienen significados distintos en ambos diccionarios, por ejemplo, el anglicismo short en el DA está restringido al ámbito del béisbol, mientras que en el DRAE se refiere a una prenda de vestir. Curiosamente, se encuentran bastantes diferencias entre los orígenes etimológicos que se atribuyen a los anglicismos en ambos diccionarios. Los 18 anglicismos que el DA registra como voces autóctonas son de apariencia totalmente española, con la excepción de 5 de ellos: pitcheo, basquetbol, club, punch y centro forward. En el DRAE se registran 14 de ellos como procedentes "del inglés" o usados en América o en México, con la excepción de 4 que también se registran como voces autóctonas: bateo, sobretodo, goleador y fanático.

Los 10 anglicismos que se definen como procedentes del inglés en el DA pertenecen a distintas tipologías (asimilado, parcialmente adaptado, crudo, derivado e hipercaracterizado), 7 de ellos están registrados en el DRAE, todos como procedentes del inglés, excepto gongo, que remite al anglicismo crudo gong. Los 34 anglicismos registrados en el DA como voces inglesas son todos crudos, de los cuales el DRAE tan sólo acepta 10, 2 de ellos, box y record, como procedentes del inglés; 5 de ellos como voces inglesas, aunque 2 de ellos con un significado más general (short y standing en el DA están vinculados al béisbol, y 3 con una modificación en la grafía, 
cocktail como cóctel, jockey como yoquey y standard como estándar). Además, 2 anglicismos son admitidos en el DA después de una modificación de la grafía, basket como basquet y penalty como penalti, ambos se registran en el DRAE. En líneas generales, los anglicismos no admitidos en el DRAE coinciden en ser anglicismos crudos en su mayoría y pertenecer principalmente a las disciplinas del rugby, el béisbol, o ser voces deportivas con equivalente en lengua española (e.g. tim y team por equipo, score por punto, o field por campo).

En el DRAE se admite un total de 59 anglicismos de los 133 analizados en el estudio, 30 de ellos como procedentes "del inglés"; 10 como voces autóctonas; 8 como voces inglesas; 7 de ellos después de una adaptación ortográfica al español; 2 que redirigen a otro anglicismo; y 1 es usado en México. Aproximadamente la mitad de estos anglicismos están gráficamente adaptados al español (asimilados, calcos léxicos, y derivados), y la otra mitad son anglicismos crudos como cross, single o rugby; aunque pertenecen a distintas disciplinas, destacan las voces generales y los anglicismos relacionados con el boxeo y el fútbol. De estos anglicismos, 29 no se registran en el DA, a pesar de ser algunos de ellos voces muy conocidas como corner, baloncesto, handicap o crack, que habían sido localizados en los periódicos americanos. Esto puede deberse a que son términos tan universales que no se consideran americanismos. Asimismo, algunos de los anglicismos estaban vinculados a deportes no tan populares en ese momento en América como el motociclismo, y ésta puede ser la causa por la cual no han sido incluidos en el diccionario.

Los 29 anglicismos definidos como procedentes "del inglés" son de distintos tipos, aunque predominan los crudos y asimilados. Los 10 registrados como voces autóctonas están todos totalmente adaptados al español, excepto welter, y las voces inglesas son todas crudas. De estos 59 anglicismos, 20 aparecieron tan sólo en el periódico mexicano, 8 en el argentino, 11 en el español, y los restantes 19 habían sido localizados al menos en dos de los periódicos. De estos anglicismos, 33 coinciden en estar admitidos en el DA. Aproximadamente la mitad son anglicismos totalmente adaptados al español (asimilados, calcos léxicos y derivados), y la otra mitad corresponde a anglicismos crudos muy internacionales. Los 26 anglicismos admitidos en el DRAE, pero no registrados en el DA, están, en su mayoría, gráficamente adaptados al español, y pertenecen a distintas disciplinas deportivas, voces deportivas y voces no generales, aunque no se encontró ninguno relativo al rugby (sólo rugby), ni al béisbol. Si tenemos en cuenta la admisión de los anglicismos por periódicos, la información se muestra en la Tabla 3:

Tabla 3: Admisión en el DA y DRAE

\begin{tabular}{|l|c|c|}
\hline Periódico & DA & DRAE \\
\hline La Afición (México) & $39,8 \%$ & $44 \%$ \\
\hline Gráfico (Argentina) & $49,1 \%$ & $40,3 \%$ \\
\hline Mundo Deportivo (España) & $27 \%$ & $67,5 \%$ \\
\hline
\end{tabular}


Como se observa en la tabla anterior, es evidente la influencia de los Estados Unidos en los periódicos analizados procedentes de México y de Argentina, frente al publicado en España.

\section{Conclusiones}

La consecuencia del origen angloamericano de la mayor parte de los deportes es la incorporación de anglicismos al lenguaje deportivo a principios del siglo $\mathrm{XX}$, cuando el deporte comenzó a convertirse en un fenómeno de masas a nivel internacional. Esta influencia es evidente en el lenguaje deportivo reflejado en los tres periódicos analizados, y es mucho más prominente en el caso de los publicados en los dos países latinoamericanos, sobre todo el mexicano, probablemente por la cercanía con Estados Unidos. Aunque en el periódico español Mundo Deportivo también se localizó un número bastante considerable de anglicismos, la diferencia con respecto a los otros dos periódicos es bastante notable, probablemente debido a la política de estado franquista sustentada sobre el patriotismo y la autarquía.

En cuanto a las prácticas deportivas en las que se adscribía un mayor número de anglicismos, en el periódico mexicano destaca la cantidad de anglicismos vinculados al béisbol y al rugby -lo que nuevamente muestra la gran influencia de los Estados Unidos-, las voces deportivas y el boxeo. En el Gráfico (periódico argentino), sin embargo, son más numerosos los anglicismos relacionados con el fútbol, aunque también se encontraron muchas voces vinculadas al rugby y al boxeo. Los anglicismos registrados en la prensa española estaban mayoritariamente relacionados con el fútbol y otros deportes menos populares, y también con voces no deportivas.

Respecto a la tipología de los anglicismos encontrados en el estudio, aunque en los tres periódicos son más numerosos los anglicismos crudos, nuevamente se encuentran diferencias entre los tres países, registrándose un porcentaje mucho más alto en el periódico argentino (78,9\%) y en el mexicano (67,9\%), en comparación con el español que tan sólo obtuvo un 33,3\% de este tipo de anglicismos. Por el contrario, es el español el medio que registró un porcentaje más alto de anglicismos asimilados $(27,6 \%)$, dato que contrasta con el número bastante inferior encontrado en el periódico argentino, tan sólo el 5,3\%, y algo más numeroso en el mexicano (19,5\%). Estos datos pueden ser reflejo del impacto socioeconómico de Estados Unidos sobre países latinoamericanos como México y Argentina, y de la menor influencia en España, en aquel momento menos abierto a influencias externas por razones políticas.

Desde un punto de vista lexicográfico, casi el 50\% del total de anglicismos está registrado en el Diccionario de Americanismos, y casi el 44\% en el Diccionario de la Lengua Española. Estos datos varían si se analizan por periódicos, pues tanto en el periódico mexicano como en el argentino el porcentaje está bastante igualado, casi un $40 \%$ de los anglicismos mexicanos se encuentra en el DA, y un 44\% en el DRAE; casi el 50\% de los anglicismos argentinos estaba en el DA, y un 40\% en el DRAE. Nuevamente se encuentran diferencias con los anglicismos españoles, de los que tan sólo un 27\% estaba registrado en el DA y, sin embargo, un 67,5\% sí lo estaba en el DRAE. Este dato puede ser consecuencia del alto número de anglicismos asimilados, voces formadas por derivación de anglicismos y calcos léxicos encontrados en el periódico español, y que al tener unas grafías aceptables dentro de la lengua española, son más propensos a ser integrados en el DRAE. 
Aunque la influencia del inglés en el lenguaje deportivo es incuestionable hoy en día, esta tendencia ya era visible en estos tres periódicos de los años 50, y mucho más evidente en el caso de los publicados en los países hispanoamericanos, no sólo desde un punto de vista cuantitativo, sino en cuanto a las distintas disciplinas en las que éstos se adscriben, y en relación también con la tipología de los mismos, en contraste con el periódico español, que tiende a utilizar un número de anglicismos mucho menor y a españolizar sus grafías.

\section{OBRAS CITADAS}

Alonso Pascual, José. 1996. Anglicismos deportivos: Uso y abuso en la información española. Valladolid: Junta de Castilla y León.

Alvar Ezquerra, Manuel. 2009. "El deporte y los términos deportivos". En Hernán-Gómez Prieto, Beatriz (Coord.), Il linguaggio dello sport. La comunicazione e la scuola. Milán: Edizioni Universitarie di Lettere Economia Diritto (LED). 149-166.

Alzugaray, Juan José. 1982. Extranjerismos en el deporte. Barcelona: Hispano Europea.

Archetti, Eduardo. 2005. "El deporte en Argentina (1914-1983)". Trabajo y Sociedad 7.VI: $1-30$.

Bergel, Martín y Pablo Palomino. 2000. "La revista El Gráfico en sus inicios: Una pedagogía deportiva para la ciudad moderna". Prismas. Revista de Historia Intelectual 4: 103-122.

Caloca Carrasco, Eloy. 2003. Recuento histórico del periodismo. México D.F.: IPN.

Castañón Rodríguez, Jesús. 1987. Anglicismos de fútbol en "Marca" (1938-1986). Tesina de Licenciatura. Universidad de Valladolid, España.

1992. "Anglicismos de fútbol en el periodismo deportivo español”. Notas y Estudios Filológicos 7: 127-147.

1998. "Anglicismos hispánicos del deporte moderno”. Apuntes... 6.1: 9-11.

2000. "Base de extranjerismos del deporte". Idioma y Deporte 3. Recuperado de http:// www.idiomaydeporte.com/base.htm

2011. La comunicación deportiva y la lengua española. Valladolid: Author's Edition.

Contreras, Lidia. 1953. "Anglicismos en el lenguaje deportivo chileno". Boletín de Filología de la Universidad de Chile VII: 177-341.

García Yebra, Valentín. 1992. "Neologismos en la prensa deportiva". En Agencia Efe-Gobierno de La Rioja, El neologismo necesario. Madrid: Fundación Efe. 187-195.

Gómez Capuz, Juan. 1997. "Towards a Typological Classification of Linguistic Borrowing (Illustrated with Anglicisms in Romance Languages)". Revista Alicantina de Estudios Ingleses 10: 81-94.

González Gómez, Marjorie. 2000. “Anglicismos usados en narraciones costarricenses en el fútbol”. Filología y Lingüística 26.2: 221-233.

Lázaro Carreter, Fernando. 1994. "El español en el lenguaje deportivo". En García Turza, Claudio, Carlos Reigosa, Pedro García Domínguez, Alberto Gómez Font y Miguel Angel Muro Munilla (Coords.), El idioma español en el deporte. Madrid: Fundación Efe. 19-35.

Lario de Oñate, Carmen y María Vázquez Amador. 2010. "Anglicismos y galicismos en El Mundo Deportivo en 1906". Files of the 9th International Conference of European Association of Languages for Specific Purposes. Tostedt: Attiko. 1-9.

Lorenzo, Emilio. 1987. "Anglicismos en la prensa". Actas de la Primera Reunión de Academias de la Lengua Española sobre el Lenguaje y los Medios de Comunicación. Madrid: Real Academia Española. 71-79.

Luna Traill, Elizabeth. 1998. "Los anglicismos deportivos en el léxico culto de once ciudades hispánicas". Boletín de Filología 37.2: 693-711.

Milic, Mira. 2013. "The Influence of English on Serbian Sports Terminology". ESP Today. 
Journal of English for Specific Purposes at Tertiary Level 1.1: 65-79.

Nomdedeu-Rull, Antoni y Melva Márquez Rojas. 2001. "Los anglicismos en la terminología del fútbol: Motivaciones y consecuencias lingüísticas". En Moreno Fernández, María Isabel (Coord.), Perspectivas recientes sobre el discurso. León: Universidad de León. $5-22$.

2002. "El léxico del fútbol en la lexicografía general monolingüe del español". En Battaner, Paz y Janet DeCesaris (Coords.), Actes del I Symposium Internacional de Lexicografia. Barcelona: Institut Universitari de Lingüística Aplicada, Universitat Pompeu Fabra. 619-640.

2003. "La terminología del deporte en los diccionarios generales del español". Revista de Lexicografia 9: 57-95.

Torrebadella-Flix, Xavier y Antoni Nomdedeu-Rull. 2013. "Foot-ball, futbol, balompié... Los inicios de la adaptación del vocabulario deportivo de origen anglosajón". RICYDE. Revista Internacional de Ciencias del Deporte IX.31: 5-22.

Olivera Beltrán, Javier. 1993. "Reflexiones en torno al origen del deporte". Apunts: Educación Física y Deportes 33: 12-23.

Otero Carvajal, Luis Enrique. 2003. "Ocio y deporte en el nacimiento de la sociedad de masas: La socialización del deporte como práctica y espectáculo en la España del primer tercio del siglo XX". Cuadernos de Historia Contemporánea 25:169-198.

Pasteur, Gabriel Angelotti. 2011. "Deporte y nacionalismo en México durante la post revolución". Revista de História do Esporte 4.1: 1-32.

Pratt, Christ. 1980. El anglicismo en el español peninsular contemporáneo. Madrid: Gredos.

Real Academia Española. 2001. Diccionario de la Lengua Española. Madrid: Espasa Calpe. Recuperado de http://www.rae.es . 2010. Diccionario de Americanismos. Lima: Santillana Ediciones Generales. Recuperado de http://www.asale.org/recursos/diccionarios/damer

Rivero Herraiz, Antonio. 2004. "Los orígenes del deporte español: El desarrollo de un nuevo componente cultural urbano". Kronos 6: 29-33.

Rodríguez González, Félix. 2007. "Variaciones en el uso de anglicismos deportivos". Donde dice... 7: 12-13.

. 2012. "Anglicismos en el mundo del deporte: Variación lingüística y sociolingüística". Boletín de la Real Academia Española 92.306: 317-341.

Sainz de Baranda, Clara. 2013. "Orígenes de la prensa diaria deportiva: El mundo deportivo". Materiales para la Historia del Deporte 11: 7-27. 
Anexos

Anexo 1: Listado de los anglicismos encontrados en los tres periódicos

\begin{tabular}{|c|c|c|c|}
\hline Deporte & $\begin{array}{c}\text { La Afición } \\
\text { México }\end{array}$ & $\begin{array}{c}\text { Gráfico } \\
\text { Argentina }\end{array}$ & $\begin{array}{c}\text { Mundo Deportivo } \\
\text { España } \\
\end{array}$ \\
\hline \multirow[t]{18}{*}{ Fútbol } & & back & \\
\hline & & ball & \\
\hline & & centro forward & \\
\hline & corner & corner & corner \\
\hline & & crack & crack \\
\hline & futbol & futbol & futbol \\
\hline & & futbolístico & futbolístico \\
\hline & & & antifútbol \\
\hline & & goalkeeper & \\
\hline & gol & gol & gol \\
\hline & & goleador & \\
\hline & & guardavalla & \\
\hline & & half & \\
\hline & & insider & \\
\hline & & shot & chut \\
\hline & penalty & & penalty \\
\hline & réferi & & \\
\hline & soccer & & \\
\hline \multirow[t]{17}{*}{ Voz no deportiva } & clown & & \\
\hline & club & club & club \\
\hline & elevadorista & & \\
\hline & fan & & \\
\hline & lider & & lider \\
\hline & ponche & & \\
\hline & rol & & \\
\hline & yarda & & yarda \\
\hline & & & comité \\
\hline & & & film \\
\hline & & & interviú \\
\hline & & & jersey \\
\hline & & cocktail & \\
\hline & & lunch & \\
\hline & & performance & \\
\hline & & sobretodo & \\
\hline & & standard & \\
\hline
\end{tabular}




\begin{tabular}{|c|c|c|c|}
\hline \multirow[t]{14}{*}{ Boxeo } & box & box & \\
\hline & boxeador & boxeador & boxeador \\
\hline & boxeo & boxeo & boxeo \\
\hline & boxer & & \\
\hline & & boxístico & \\
\hline & nelson & & \\
\hline & noquear & knockout & \\
\hline & oper & & \\
\hline & ring & ring & ring \\
\hline & round & round & \\
\hline & welter & & \\
\hline & & punch & \\
\hline & & & catcher \\
\hline & & & gongo \\
\hline \multirow[t]{22}{*}{ Béisbol } & average & & \\
\hline & bateo & & \\
\hline & béisbol & & \\
\hline & fildeador & & \\
\hline & fildeo & & \\
\hline & flay & & \\
\hline & foul & foul & \\
\hline & hit & & \\
\hline & home run & & \\
\hline & innings & & \\
\hline & jonrón & & \\
\hline & leftfield & & \\
\hline & out & & \\
\hline & outfield & & \\
\hline & pasbol & & \\
\hline & pitcheo & & \\
\hline & pitcher & & \\
\hline & short & & \\
\hline & softbol & softball & \\
\hline & standings & & \\
\hline & swing & & \\
\hline & wild & & \\
\hline
\end{tabular}




\begin{tabular}{|c|c|c|c|}
\hline \multirow[t]{19}{*}{ Rugby } & back & & \\
\hline & backfield & & \\
\hline & coach & & \\
\hline & down & & \\
\hline & fullback & full-back & \\
\hline & halfback & & \\
\hline & quarterback & & \\
\hline & rugby & rugby & \\
\hline & single-wing & & \\
\hline & tackle & & \\
\hline & tailback & & \\
\hline & touch & touch & \\
\hline & touchdown & & \\
\hline & & forward & \\
\hline & & handling & \\
\hline & & scrum & \\
\hline & & scrum-half & \\
\hline & & try & \\
\hline & & winger & \\
\hline \multirow[t]{11}{*}{ Voz deportiva } & bowl & & \\
\hline & field & field & \\
\hline & handicap & handicap & handicap \\
\hline & manager & manager & \\
\hline & match & match & \\
\hline & player & & \\
\hline & record & & recordman \\
\hline & score & score & \\
\hline & singles & single & \\
\hline & team & team & \\
\hline & tims & & \\
\hline \multirow[t]{11}{*}{ Otros deportes } & volibol & & balonbolea \\
\hline & volibolera & & \\
\hline & & & campo a través \\
\hline & & & ciclo-cross \\
\hline & & & ciclo-crossman \\
\hline & & & cross \\
\hline & & & esprinter \\
\hline & hockey( sobre hielo) & & hockey \\
\hline & tenis & tenis & tenis mesa \\
\hline & & court & \\
\hline & & & waterpolista \\
\hline
\end{tabular}




\begin{tabular}{|c|c|c|c|}
\hline \multirow[t]{5}{*}{ Baloncesto } & basquetbol & & \\
\hline & baloncesto & & baloncesto \\
\hline & basketball & basketball & \\
\hline & básket & basket & \\
\hline & & basketballer & \\
\hline \multirow[t]{5}{*}{ Deportes acuáticos } & & pack & \\
\hline & & rowing club & \\
\hline & & yachtsman & \\
\hline & & yachting & \\
\hline & & yacht & yate \\
\hline \multirow[t]{5}{*}{ Hípica } & entry & & \\
\hline & furlong & & \\
\hline & handicapper & & \\
\hline & tiemop & & \\
\hline & & turf & \\
\hline
\end{tabular}

